\title{
Genetic Dimension of Intervertebral Disc Degeneration: Polymorphism of Matrix Metalloproteinase 1 and 3 in the North Iranian Population
}

\author{
Alia SABERI ${ }^{1}$, Zivar SALEHII ${ }^{1,2}$, Bahram NADERINABI ${ }^{3}$, Sahar Hojaat ANSARI ${ }^{4}$, Sohail MASHAYEKHI ${ }^{4}$ \\ ${ }^{1}$ Guilan University of Medical Sciences, School of Medicine, Poursina Hospital, Neuroscience Research Center, Department of Neurology, \\ Rasht, Iran \\ 2University of Guilan, Faculty of Sciences, Department of Biology, Rasht, Iran \\ ${ }^{3}$ Guilan University of Medical Sciences, Anesthesiology Research Center, Rasht, Iran \\ ${ }^{4}$ Guilan University of Medical Sciences, Rasht, Iran
}

\section{ABSTRACT}

AIM: The etiology of intervertebral disc degeneration is still vague and both genetic and environmental factors are assumed as the main causes. One of the proposed genetic factors is the polymorphism of matrix metalloproteinases (MMPs) genes. The aim of this study was to explore the relationship between two polymorphisms (MMP-1-755 T/G [rs498186] and MMP-3 A/C [rs632478]) and disc degeneration.

MATERIAL and METHODS: We performed a case-control study on 130 cases with intervertebral disc degeneration confirmed by magnetic resonance imaging (MRI) and 210 healthy individuals. The Schneiderman criterion was used to determine the severity of the disc degeneration. Blood samples were collected from the participants. The genotyping was performed by the polymerase chain reaction-restriction fragment length polymorphism (PCR-RFLP) method. Odds ratios and 95\% Cls were determined as measures of the strength of association between genotypes and disc degeneration.

RESULTS: The most frequent intervertebral disc degeneration was observed in age range of 31-40 years (43.2\%). A significant association was found between the MMP-3 polymorphism and disc degeneration $(\mathrm{p}<0.001)$. The homozygote CC was associated with an increased risk of disc degeneration compared with the $A A$ genotype $(O R=5.25 ; 95 \% \mathrm{Cl}=2.82-9.77, p<0.001)$. We did not find any significant association of the MMP-1 polymorphism with disc degeneration $(p=0.95)$.

CONCLUSION: The MMP-3 [rs632478] polymorphism may contribute to susceptibility to disc degeneration. To confirm our findings, additional well-designed studies in diverse ethnic populations are required.

KEYWORDS: Polymorphism, Matrix metalloproteinase-1, Matrix metalloproteinase-3, Intervertebral disc degeneration

\section{INTRODUCTION}

I ntervertebral disc degeneration is a multifactorial disorder of the musculo-skeletal system and one of the main causes of backache and disability (1). Intervertebral disc degeneration is irreversible and progressive $(28,32)$. It usually occurs at the third or fourth decades of life (31). Degeneration can lead to herniation, radiculopathy, myelopathy, spinal stenosis, and degenerative spondylolisthesis (19). Although its etiology and pathogenesis are still vague, both genetic and environmental factors are assumed as the main causes (11). Age, mechanical pressure, genetic factors and biochemical and inflammatory changes are important factors $(11,23,31,33)$. Studies have highlighted the strong family predisposition to disc degeneration and herniation $(10,18,29)$. Findings of two 
studies a decade ago reported $60 \%$ impact of heredity on this process $(5,25)$. Moreover, different genes have been blamed for disc degeneration development $(2,6,14)$.

Intervertebral disc degeneration has a unique outer structure made of annulus fibrosus and an inner nucleus pulposus with elasticity that makes it resistant to compression and distribution of power in the spinal cord (30). Developing intervertebral disc degeneration generates a multi-step process, one major step of which is the deterioration of matrix (20). Today, the majority of research emphasizes the importance of discovering the mechanism of extracellular matrix deterioration, particularly regulation of gene expression. According to various reports, polymorphism in a number of genes such as Agrecan, interleukin-1 and 6, vitamin D receptor and matrix metalloproteinase genes is associated with an increased risk of intervertebral disc degeneration $(7,30,31)$.

Studies have found a number of matrix metalloproteinase (MMPs) (including MMP type 1,28,32,23,33,10,8,25,7,16) associated with disc degeneration (33). These proteases are the most important catabolic enzymes in the destruction of intervertebral discs $(4,21)$. In humans, there are 23 distinct MMPs comprising secreted and transmembrane proteins. MMPs are commonly classified based on the type of substrate, protein structure and cell localization into namely Collagenase, Gelatinase and Stromelysin and Matrilysin and membrane-type matrix metalloproteinases (30). MMP-mediated remodeling of the pericellular microenvironment is therefore essential for many physiological processes. In degraded tissue, there is an increase in many MMPs, including MMP-1, 2, 3, 7, 9, 13, and 28 , often according to the severity of degeneration (19). Matrix metalloproteinase 1 (MMP-1=interstitial collagenase) has a specific ability to degrade type-I collagen, whereas MMP-3 (Stromelysin) degrades a broader range of substrates (e.g. fibronectin, laminin, collagens III, IV, IX, and X, and cartilage proteoglycans), and may also affect the expression of other MMPs (17).

Given the importance of genetic factors in patients with intervertebral degenerative disc, this study sought to find the relationship between polymorphism of matrix metalloproteinases- 1 and -3 with intervertebral disc degeneration, for the first time in a population of the Guilan province in northern Iran.

\section{MATERIAL and METHODS}

This hospital-based case-control study included 130 patients with newly diagnosed lumbosacral disc degeneration referred to the spine clinic of Guilan University of Medical Sciences, Iran, between September 2013 and December 2015. The patients consisted of 68 men and 62 women, whereas the controls included 210 disease-free subjects recruited from the same institute with similar age and sex distribution (119 men, 91 women). The magnetic resonance imaging (MRI) findings of the healthy controls showed normal intervertebral disc tissue.

The participants' demographic data, history and imaging findings were entered in a designed checklist. Positive family history was considered as having any evidence of intervertebral disc degeneration in first- and/or second-degree family docu- mented by whole spinal MRI or typical history. Positive history of smoking was defined according to the Standard National Survey on Drug Use and Health current cigarette smoking variable definition (NSDUH-S)(23). The level of occupation load was scaled based on US-National Institute for Occupational Safety and Health (NIOSH) as low/moderate and high (32). The ethical committee of Guilan University of Medical Sciences approved the study by code of IR. GUMS.REC.1394.56 and all study subjects supplied a written informed consent that was subsequently archived. This study was performed in accordance with the declaration of Helsinki (1989).

\section{Imaging Procedure}

All participants underwent an MRI examination using a noncontrast 1.5 Tesla MRI and T2-weighted fast spin-echo (2700/110, TR/TE) for 12 sagittal and axial scans of the whole spine with $0.5 \mathrm{~mm}$ slices. The severity of disc degeneration was assessed according to Schneiderman's classification in the most destructed disc (22).

\section{Genotyping}

Two $\mathrm{ml}$ of whole blood was collected in vacutainers containing ethylene diamine tetra acetic acid (EDTA) for deoxyribonucleic acid (DNA) isolation. Genomic DNAs were isolated using the GPP solution kit (Gen Pajoohan Pouya, Iran) following standard procedures. DNA purity and concentration were determined spectrophotometrically at 260 to $280 \mathrm{~nm}$. Each DNA sample was stored in TE buffer $(5 \mathrm{mM}$ Tris- $\mathrm{HCl}, 0.1 \mathrm{mM}$ EDTA, $\mathrm{pH} 8.5$ ) at $-20^{\circ} \mathrm{C}$ until analysis.

The genotypes of MMP-1 and MMP-3 (rs498186 and rs632478, respectively) were detected by polymerase chain reaction-restriction fragment length polymorphism (PCR-RFLP). Amplifications were carried out using primers designed by Oligo primer analysis software (Version 7.54, Molecular Biology Insights, USA). Primer sequences for PCR amplification of each polymorphism were as follows: MMP1 (rs498186), forward 5'-GTTATCTCATACTCCGCCTGT -3' and reverse 5'-CCTTCTGCCTITGTTAAGCTG -3'; MMP-3 (rs632478), forward 5'- TTCACATCACTGCCACCACT-3' and reverse 5'- GCCCATITTGCTTCCTCTCA -3'. Each reaction mixture $(25 \mu \mathrm{l})$ contained $30 \mathrm{ng}$ DNA template, 1x PCR buffer, $1.5 \mathrm{mM} \mathrm{MgCl}, 0.2 \mathrm{mM}$ dNTP, $0.5 \mu \mathrm{M}$ each primer and 1.5 $U$ Taq DNA polymerase (Bioflux, Japan). Similarly, the PCR conditions for both polymorphisms of the MMP-1 and MMP-3 were as follows: initial denaturation at $95^{\circ} \mathrm{C}$ for 5 minutes, 35 cycles of denaturation at $95^{\circ} \mathrm{C}$ for 45 seconds, annealing at $56{ }^{\circ} \mathrm{C}$ (MMP-1) and $57^{\circ} \mathrm{C}$ (MMP-3) for 40 seconds, with a final step at $72{ }^{\circ} \mathrm{C}$ for 5 minutes to allow a complete extension of the PCR fragment.

The PCR amplicons generated for MMP-1 (462 bp) and MMP3 (519 bp) were subjected to restriction digestion (Figures 1 and 3). TspRI and Hphl restriction enzymes were used to detect polymorphisms in MMP1and MMP3, respectively. PCR products with a T at the MMP-1 (rs498186) polymorphic site were digested into two 259 and 203 bp fragments, while those with $\mathrm{G}$ were not because of the absence of the TspRI restriction site (Figure 2). The MMP-3 (rs632478) genotypes were assessed as follows: a single 519 bp fragment for the AA 


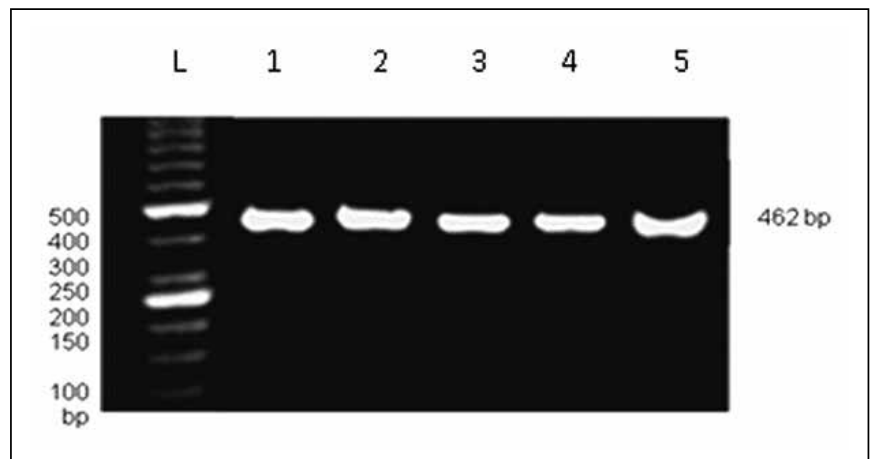

Figure 1: Agarose gel electrophoresis stained by ethidium bromide after PCR amplification of MMP-1. L ladder 1-5: amplified fragment.

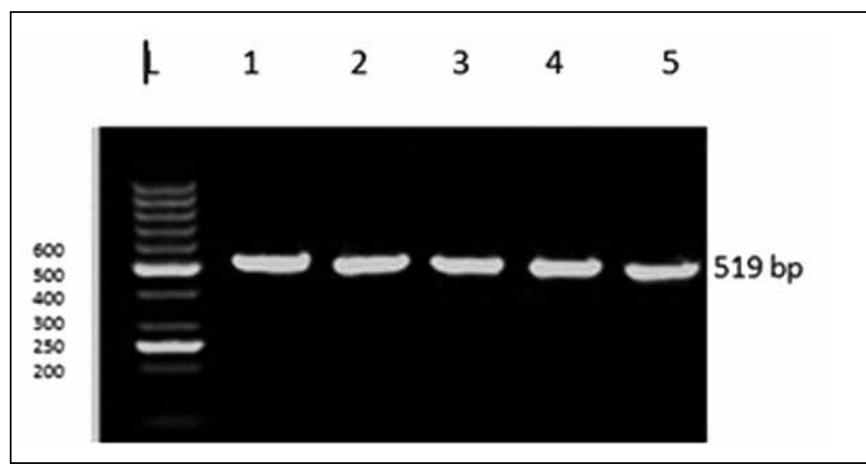

Figure 3: Agarose gel electrophoresis stained by ethidium bromide after PCR amplification of MMP-3. L ladder 1-5: amplified fragment.

genotype; two fragments of 350 and 169 bp for the CC; and three fragments of 519,350 and $169 \mathrm{bp}$ for the AC genotype (Figure 4). The PCR-RFLP products were separated on $2 \%$ agarose gel and visualized by ethidium bromide staining. All the samples with ambiguous results were repeated to ensure quality control purposes.

\section{Statistical Analysis}

Statistical analyses were carried out using SPSS software version 19. Allelic frequencies were estimated by the "counting method" and differences in allele frequencies between case and control subjects were tested using the likelihood ratio $x^{2}$ tests for $2 £ 2$ tables (two alleles, case vs. control subjects). The odds ratio (OR) and range with $95 \%$ confidence interval $(\mathrm{Cl})$ were calculated for the presence of the reference genotype and allele using a logistic regression model. Statistical significance was set at $p<0.05$.

\section{RESULTS}

In the present study, a total of 340 subjects including 130 patients with disc degeneration and 210 disease-free control subjects were evaluated. The mean age was $37.9 \pm 8.8$ years for the subjects and $35.7 \pm 7.4$ years for the controls $(p=0.157)$. The main characteristics of the patients are summarized in Table I.

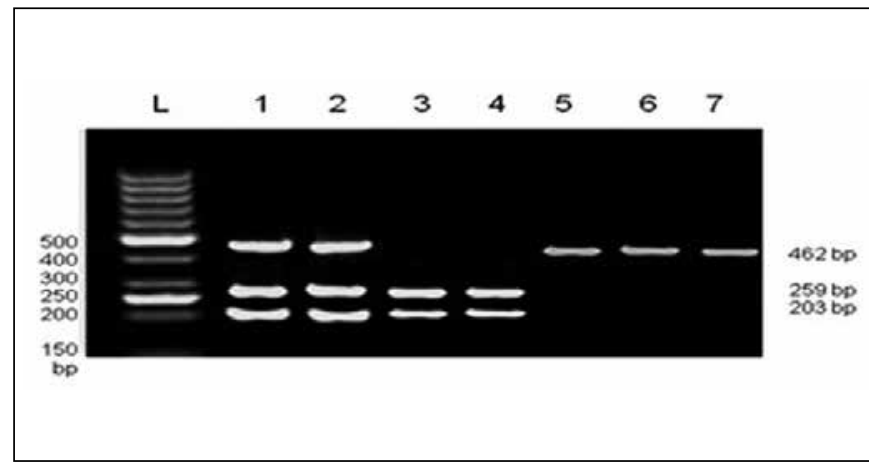

Figure 2: RFLP analysis of the MMP-1 polymorphism. L, DNA ladder, 1 and 2: GT heterozygote, 3 and 4: TT homozygote, 5, 6 and 7: GG homozygote.

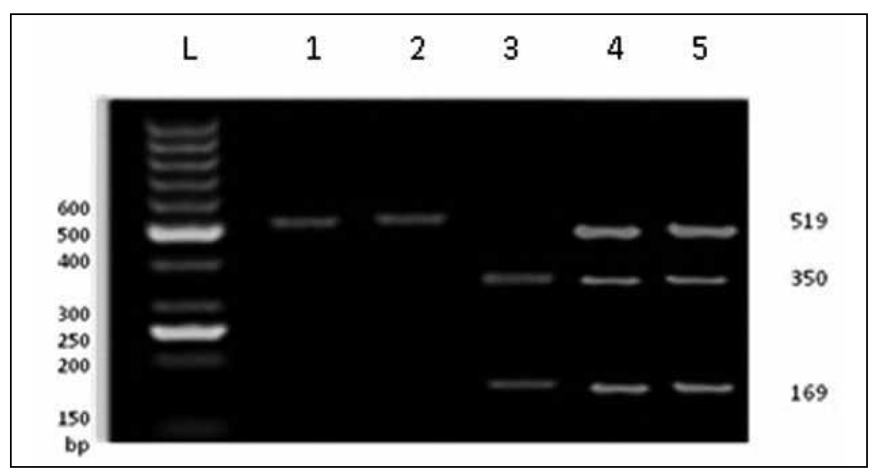

Figure 4: RFLP analysis of the MMP-3 polymorphism. L DNA ladder 1, 2: AA homozygote, 3: CC homozygote and 4, 5: AC heterozygote.

Among the 130 patients with intervertebral disc degeneration, $18.2 \%$ of patients had been diagnosed for less than six months, $38.6 \%$ six months to one year, $15.9 \%$ one to two years, $20.5 \%$ two to five years and $6.8 \%$ more than five years. Interestingly, the highest frequency belonged to patients with disc protrusion (59.1\%), followed by disc bulging (25\%), extrusion (11.4\%) and migration (4.5\%) based on Schneiderman's classification.

The distribution of the MMP-1 (rs498186) and MMP-3 (rs632478) polymorphisms was compared using the Chisquare test. Genotype and allele frequencies of the MMP-1 and MMP-3 polymorphism in patients with disc degeneration and controls are shown in Tables II and III. The frequencies of the $A A, A C$ and $C C$ genotypes of MMP-3 were $52.38 \%$, $35.71 \%$ and $11.9 \%$ in controls and $27.69 \%, 39.23 \%$ and $33.07 \%$ in the cases, respectively. Four genetic models (codominant, dominant, recessive and over-dominant) were applied for the analysis of the SNPs. In a recessive model (polymorphic homozygous genotype vs. heterozygous + wildtype homozygous genotypes), the CC genotype of MMP3 was associated with susceptibility to disc degeneration compare to that of the $A C+A A$ genotype $(O R=3.65 ; 95 \%$ $\mathrm{Cl}=2.09-6.37, \mathrm{p}<0.001$ ). In a co-dominant model (polymorphic homozygous genotype vs. wild-type homozygous genotype), we found that the CC genotype of MMP-3 was correlated with 
a higher risk of disc degeneration when compared with that of the AA genotype $(\mathrm{OR}=5.25 ; 95 \% \mathrm{Cl}=2.82-9.77, \mathrm{p}<0.001)$. Comparison with the control group MMP-3 allele $\mathrm{C}$ showed a significant difference in disc degeneration cases $(\mathrm{OR}=2.62$; $95 \% \mathrm{Cl}=1.90-3.62, \mathrm{p}<0.001)$. On the contrary, no significant difference was observed in the distribution of MMP-1 polymorphism in cases and controls both at the genotype and allele levels $\left(X^{2}=3.60 ; P=0.16, X^{2}=0.003 ; p=0.95\right)$.

No significant relationship was found between the severity of intervertebral disc degeneration and genotypes of MMPs1 and $3(p=0.690, p=0.931$, respectively), and there was no association with the MMP alleles ( $p>0.05)$.

\section{DISCUSSION}

Beside environmental factors, the genetic background plays an important role in the development of disc degeneration (21). One of the most important stages of disc degeneration is destruction of its matrix by enzymes such as matrix metalloproteinase $(17,19,22,24)$. MMP is widely considered to play a role in disc degeneration by degrading collagen type II, IX, X and aggrecan found in the matrix (3). The result of a study conducted by Fang and Jiang demonstrated that IL-1ß and high mobility group box 1 (HMGB1) additively promotes the release of inflammatory cytokines and the expression of MMPs in human IVD cells (9).

Matrix metalloproteinase-3 (Stromelysin 1) is an important member of the MMP family and has a critical role in the regeneration of connective tissue (16). However, in high concentrations it is known as the most important cause of intervertebral disc degeneration. It has also been shown that MMP-1 expression is associated with the degradation of the matrix in disc degeneration (8). Promoter polymorphisms have been identified for both MMP-1 and MMP-3. Variants in the promoter region can function by modulating transcription and leading to unusual protein expression.

The results of present study revealed a significant association between the MMP-3 A/C [rs632478] polymorphism and intervertebral disc degeneration. Its homozygous variant [CC] manifested five-fold positive significant risk for disc degeneration relative to the AA variant. Moreover, subjects with the variant genotypes $(\mathrm{CC}+\mathrm{AC})$ showed an overall increased risk of disc degeneration more than two-fold relative to AA carriers. Also the presence of [C] allele increased the risk of disc degeneration near two-fold in relation to the $A$ allele. However, the MMP-1G allele frequency in our study of mostly patients with disc degeneration was consistent with the frequencies in controls. Thus, the risk of disc degeneration does not appear to be influenced by the MMP-1 rs498186 genotype.

So far, there is no report concerning the relationship of MMP1 rs498186 and MMP-3 rs632478 genetic polymorphism with disc degeneration. Song et al. reported that individuals with the presence of $D$ allele for the -1607 promoter polymorphism of MMP-1 (rs1799750) are about 1.5 times more susceptible to develop degenerative disc disease when compared with those

Table I: Demographic Characteristics of Subjects Included in Two Groups of Study Based on Having Inter-Vertebral Disc Degeneration

\begin{tabular}{|c|c|c|c|c|}
\hline Variable & Status & $\begin{array}{l}\text { Group with Intervertebral disc } \\
\text { degeneration }(n=130) n(\%)\end{array}$ & $\begin{array}{l}\text { Control Group } \\
(n=210) n(\%)\end{array}$ & $p$ value \\
\hline \multirow{2}{*}{ Sex } & Male & $68(52.3)$ & $119(56.7)$ & \multirow{2}{*}{0.63} \\
\hline & Female & $62(47.7)$ & $91(43.3)$ & \\
\hline \multirow{3}{*}{ Age (year) } & $20-30$ & $30(23.0)$ & $65(31.0)$ & \multirow{3}{*}{0.61} \\
\hline & $31-40$ & $56(43.2)$ & $80(38.0)$ & \\
\hline & $41-50$ & $44(33.8)$ & $65(31.0)$ & \\
\hline Age (year) & & $37.9 \pm 8.8$ & $35.7 \pm 7.4$ & 0.157 \\
\hline \multirow{2}{*}{ Smoking } & Yes & $21(16.2)$ & $31(14.8)$ & \multirow{2}{*}{0.87} \\
\hline & No & $109(83.8)$ & $179(85.2)$ & \\
\hline \multirow{3}{*}{ BMI } & $19-25$ & $68(52.3)$ & $82(39.0)$ & \multirow{3}{*}{0.38} \\
\hline & $26-30$ & $53(40.8)$ & $111(52.9)$ & \\
\hline & $>30$ & $9(6.9)$ & $17(8.1)$ & \\
\hline BMI & & $25.42 \pm 2.95$ & $25.9 \pm 2.73$ & 0.37 \\
\hline \multirow{2}{*}{ Family history } & Yes & $65(50)$ & $45(21.4)$ & \multirow{2}{*}{0.0001} \\
\hline & No & $65(50)$ & $165(78.6)$ & \\
\hline \multirow{2}{*}{ Level of occupation load (NIOSH) } & High & $30(23.1)$ & $34(16.2)$ & \multirow{2}{*}{0.38} \\
\hline & Low/moderate & $100(76.9)$ & $176(83.8)$ & \\
\hline
\end{tabular}


having $\mathrm{G}$ allele only (26). However, Jacobsen et al. revealed no difference in the frequency of the MMP-1 rs1799750 2G allele in patients with disc herniation compared with controls. They also found that the patients homozygous for the $2 \mathrm{G}$ allele had more pain and reduced function compared with those carrying the $1 \mathrm{G}$ allele (13).
Takahashi et al. found that the MMP-3 5A5A and 5A6A genotype in the elderly was associated with a significantly larger number of degenerative discs than the $6 \mathrm{~A} 6 \mathrm{~A}$, but there was no significant difference in the youth (27). More closely, similar observations have been reported by Yuan et al. in the Chinese population and their findings suggested that people with the mutation genotypes 5A of MMP-3 and/or A of VDR-

Table II: Genotype Frequencies of MMP-1 and MMP-3 Polymorphisms in Patients with Disc Degeneration and Controls

\begin{tabular}{|c|c|c|c|c|c|}
\hline Genetic mode & Genotypes & Patients n (\%) & Controls n (\%) & OR $(95 \% \mathrm{Cl})$ & $p$ value \\
\hline \multicolumn{6}{|c|}{ MMP-1(rs498186) } \\
\hline \multirow[t]{3}{*}{ Co-dominant } & $\pi$ & $31(23.84)$ & $59(28.09)$ & 1.00 & \\
\hline & $\mathrm{TG}$ & $93(71.53)$ & $132(62.85)$ & $1.34(0.80-2.23)$ & 0.25 \\
\hline & GG & $6(4.61)$ & 19(9.04) & $0.60(0.21-1.65)$ & 0.32 \\
\hline \multirow[t]{2}{*}{ Dominant } & $\pi$ & $31(23.84)$ & $59(28.09$ & 1.00 & \\
\hline & $G G+T G$ & $99(76.15)$ & $151(71.90)$ & $1.26(0.76-2.08)$ & 0.36 \\
\hline \multirow[t]{2}{*}{ Recessive } & $T+T G$ & 124(95.38) & 191(90.95) & 1.00 & \\
\hline & $\mathrm{GG}$ & $6(4.61)$ & 19(9.04) & $0.48(0.18-1.25)$ & 0.13 \\
\hline \multirow[t]{2}{*}{ Over-dominant } & $G G+T$ & $37(28.46)$ & $78(37.14)$ & 1.00 & \\
\hline & TG & $93(71.53)$ & $132(62.85)$ & $1.48(0.92-2.38)$ & 0.10 \\
\hline \multicolumn{6}{|c|}{ MMP-3(rs632478) } \\
\hline \multirow[t]{3}{*}{ Co-dominant } & AA & $36(27.69)$ & $110(52.38)$ & 1.00 & \\
\hline & $A C$ & $51(39.23)$ & $75(35.71)$ & $2.07(1.23-3.48)$ & 0.005 \\
\hline & $\mathrm{CC}$ & $43(33.07)$ & $25(11.9)$ & $5.25(2.82-9.77)$ & $<0.001$ \\
\hline \multirow[t]{2}{*}{ Dominant } & $\mathrm{AA}$ & $36(27.69)$ & $110(52.38)$ & 1.00 & \\
\hline & $A C+C C$ & $94(72.3)$ & $100(47.61)$ & $2.87(1.79-4.59)$ & $<0.001$ \\
\hline \multirow[t]{2}{*}{ Recessive } & $A A+A C$ & $87(66.92)$ & 185(88.09) & 1.00 & \\
\hline & $\mathrm{CC}$ & $43(33.07)$ & $25(11.9)$ & $3.65(2.09-6.37)$ & $<0.001$ \\
\hline \multirow[t]{2}{*}{ Over-dominant } & $A A+C C$ & $79(60.76)$ & $135(64.28)$ & 1.00 & \\
\hline & $A C$ & $51(39.23)$ & $75(35.71)$ & $1.16(0.74-1.82)$ & 0.51 \\
\hline
\end{tabular}

OR: Odds ratio, 95\% Cl: 95\% confidence interval. Bold values indicate $p<0.05$.

Table III: Association Between MMP-1(rs498186) and MMP-3(rs632478) Alleles and Susceptibility of Disc Degeneration

\begin{tabular}{|c|c|c|c|c|c|}
\hline Polymorphic site & Allele n (\%) & Patients n (\%) & Controls $(95 \% \mathrm{Cl})$ & OR & $p$ value \\
\hline \multicolumn{6}{|l|}{ MMP-1(rs498186) } \\
\hline & $\mathbf{T}$ & 155(59.61) & 250(59.52) & 1.00 & \\
\hline & G & $105(40.38)$ & $170(40.47)$ & $0.99(0.72-1.36)$ & 0.98 \\
\hline \multicolumn{6}{|l|}{ MMP-3(rs632478) } \\
\hline & A & $123(47.30)$ & 295(70.23) & 1.00 & \\
\hline & $\mathrm{C}$ & $137(52.69)$ & 125(29.79) & $2.62(1.90-3.62)$ & $<0.001$ \\
\hline
\end{tabular}

OR: Odds ratio; 95\% Cl: 95\% confidence interval. Bold value indicates $p<0.05$. 
Apa may have increased risk of developing lumbar disc degeneration if they are exposed to whole-body vibration and/or bending/twisting (31). In another study, Zawilla et al. investigated that mutant allele 5A of MMP-3 and mutant allele $T$ of VDR were significantly associated with lumbar disc degeneration (32). The conflicting results of these reports may be due to differences in sample sizes, ethnic groups, genetic heterogeneity in the pathogenesis of disc degeneration and the impact of other genetic and environmental factors.

We have also found that there is no significant relationship between the severity of disc degeneration and MMP-1 and MMP-3 polymorphisms. However, another study by Zigouris et al. found a strong link between expression of MMP-1 and MMP-3 and the grade of disc degeneration (34). Efforts by Le Maitre et al. to seek the cells that express the enzymes MMP 1 and 3 in patients with disc degeneration unveiled an increased number of these cells along with the severity of degeneration (15). Also in the Japanese population, having either one or two copies of the MMP-3 5A allele in the elderly, but there was no significant difference in the young population (27).

In the present study, the number of men was a little more than women. Yet, no difference was observed between the groups in terms of gender. In our geographical setting which is full of active farm fields, women are vigorously involved in farming and so suffer from low back pain due to disc degeneration and other musculoskeletal disorders and this can explain the fair equality of genders in our study. Most of our study participants were young adults. As both groups were the same, we cannot blame environmental and genetic causes in youth. Apparently, geographical, physical and clinical conditions of the youngest persons facilitate their cooperation in the study. Yet, in a study by Williams et al., most participants were old women (67\%) with mean age of 57.7 years old (1).

Our study showed no significant relationship between smoking and intervertebral disc degeneration, whereas some other similar studies concluded that smoking can be a risk factor exposing people to disc degeneration $(12,31,32)$. The impact of this factor would be more apparent with bigger study sample size.

Finally, our study revealed that family history of intervertebral disc degeneration was significantly higher in the cases than the control group. Zawilla's study also has the same findings. To sum, the importance of genetic factors in exposing people to disc degeneration is remarkable and worthy of consideration (32), as our results confirm this fact.

Some limitations of our study are as follows; we only evaluated two SNPs in the MMP-1 and MMP-3 genes, which was inadequate to assess the disc degeneration risk for gene studies. However, numerous factors act individually and together to influence on the risk of disc degeneration disease. So, we should involve more factors in our future work.

\section{CONCLUSION}

MMP-3 rs632478 polymorphism may contribute to increased susceptibility to disc degeneration. However, MMP-1 rs498186 was not associated with disc degeneration in the Iranian population. Moreover, the mechanisms underlying this association need to be further explored. Further studies investigating the role of MMPs genetic variants in disc degeneration and replication of the present study in diverse ethnic groups are needed to better understand the pathobiology of disc degeneration.

\section{ACKNOWLEDGMENTS}

This study is extracted from a post-doctoral thesis in Guilan University of Medical Sciences. The authors also express their special thanks to Guilan Neuroscience Research Center affiliated to Guilan University of Medical Sciences, and Genetic laboratory of Faculty of Basic Sciences in University of Guilan.

\section{REFERENCES}

1. Adams MA, Roughley $\mathrm{PJ}$ : What is intervertebral disc degeneration, and what causes it? Spine 31(18):2151-2161, 2006

2. Ala-Kokko L: Genetic risk factors for lumbar disc disease. Ann Med 34(1):42-47, 2002

3. Aras AB, Guven M, Balak N, Ayan E, Bozkurt Uyar S, Elmaci I: Evaluation of the association between matrix metalloproteinase 11 and intervertebral disc disease. Turk Neurosurg 26(2):274-279, 2016

4. Bachmeier BE, Nerlich A, Mittermaier N, Weiler C, Lumenta C, Wuertz K, Boos N: Matrix metalloproteinase expression levels suggest distinct enzyme roles during lumbar disc herniation and degeneration. Eur Spine J 18(11):1573-1586, 2009

5. Battie MC, Videman T, Gibbons LE, Fisher LD, Manninen H, Gill K: 1995 Volvo Award in clinical sciences. Determinants of lumbar disc degeneration. A study relating lifetime exposures and magnetic resonance imaging findings in identical twins. Spine 20(24):2601-2612, 1995

6. Battié MC, Videman T, Kaprio J, Gibbons LE, Gill K, Manninen $\mathrm{H}$, Saarela J, Peltonen L: The twin spine study: Contributions to a changing view of disc degeneration. Spine J 9(1):47-59, 2009

7. Canbay S, Turhan N, Bozkurt M, Arda K, Caglar S: Correlation of matrix metalloproteinase-3 expression with patient age, magnetic resonance imaging and histopathological grade in lumbar disc degeneration. Turk Neurosurg 23(4):427-433, 2013

8. Chou PH, Wang ST, Yen MH, Liu CL, Chang MC, Lee OK: Fluid-induced, shear stress-regulated extracellular matrix and matrix metalloproteinase genes expression on human annulus fibrosus cells. Stem Cell Res Ther 7:34, 2016

9. Fang $F$, Jiang $D: I L-1 \quad \beta / H M G B 1$ signaling promotes the inflammatory cytokines release via TLR signaling in human intervertebral disc cells. Biosci Rep 36(5): pii: e00379, 2016

10. Heikkila JK, Koskenvuo M, Heliovaara M, Kurppa K, Riihimaki $H$, Heikkila K, Rita H, Videman T: Genetic and environmental factors in sciatica. Evidence from a nationwide panel of 9365 adult twin pairs. Annal Med 21(5):393-398, 1989 
11. Higashino K, Matsui Y, Yagi S, Takata Y, Goto T, Sakai T, Katoh S, Yasui N: The alpha2 type IX collagen tryptophan polymorphism is associated with the severity of disc degeneration in younger patients with herniated nucleus pulposus of the lumbar spine. Int Orthop 31:107-111, 2007

12. Humphries SE, Martin S, Cooper J, Miller G: Interaction between smoking and the stromelysin-1 (MMP3) gene $5 \mathrm{~A} / 6 \mathrm{Apromoter}$ polymorphism and risk of coronary heart disease in healthy men. Ann Hum Genet 66(Pt 5-6):343-352, 2002

13. Jacobsen LM, Schistad EI, Storesund A, Pedersen LM, Espeland A, Rygh LJ, Røe C, Gjerstad J: The MMP1 rs1799750 2G allele is associated with increased low back pain, sciatica, and disability after lumbar disk herniation. Clin J Pain 29(11):967-971, 2013

14. Kalb S, Martirosyan NL, Kalani MYS, Broc GG, Theodore $\mathrm{N}$ : Genetics of the degenerated intervertebral disc. World Neurosurg 77(3-4): 491-501, 2012

15. Le Maitre CL, Freemont AJ, Hoyland JA: Localization of degradative enzymes and their inhibitors in the degenerate human intervertebral disc. J Pathol 204(1):47-54, 2004

16. Lesauskaite V, Sinkūnaite G, Benetis R, Grabauskas V, Vaskelyte J, Smalinskiene A, Simonyte S, Jariene G, Tatarūnas V, Klumbiene J, Petkeviciene J, Kinduris S, Giedraitis S, Sakalauskas J, Bolys R, Sirvinskas E, Lenkutis T, Pangonyte D: Matrix metalloproteinase-3 gene polymorphism and dilatative pathology of ascending thoracic aorta. Medicina (Kaunas) 44(5):386-391, 2008

17. López-Otín C, Matrisian LM: Emerging roles of proteases in tumour suppression. Nat Rev Cancer 7(10):800-808, 2007

18. Matsui $H$, Kanamori M, Ishihara H, Yudoh K, Naruse $Y$, Tsuji $H$ : Familial predisposition for lumbar degenerative disc disease. A case-control study. Spine 23(9):1029-1034, 1998

19. Mayer JE, latridis JC, Chan D, Qureshi SA, Gottesman O, Hecht AC: Genetic polymorphisms associated with intervertebral disc degeneration. Spine J 13(3):299-317, 2013

20. Munkert A, Helmchen U, Kemper MJ, Bubenheim M, Stahl RA, Harendza S: Characterization of the transcriptional regulation of the human MT1-MMP gene and association of risk reduction for focal-segmental glomerulosclerosis with two functional promoter SNPs. Nephrol Dial Transplant 24:735-742, 2009

21. Nagase H, Visse R, Murphy G: Structure and function of matrix metalloproteinases and TIMPs. Cardiovasc Res 69(3):562573, 2006

22. Pike J, Meyer M: The vitamin D receptor: New paradigms for the regulation of gene expression by 1,25-dihydroxyvitamin D3. Rheum Dis Clin N Am 39: 255-269, 2010
23. Roughley PJ: Biology of intervertebral disc aging and degeneration: Involvement of the extracellular matrix. Spine 29(23):2691-2699, 2004

24. Ryan H, Trosclair A, Gfroerer J: Adult current smoking: Differences in definitions and prevalence estimates-NHIS and NSDUH, 2008. J Environ Public Health 2012:918368, 2012

25. Sambrook PN, MacGregor AJ, Spector TD: Genetic influences on cervical and lumbar disc degeneration: A magnetic resonance imaging study in twins. Arthritis Rheum 42(2):366372, 1999

26. Song YQ, Ho DW, Karppinen J, Kao PY, Fan BJ, Luk KD, Yip SP, Leong JC, Cheah KS, Sham P, Chan D, Cheung KM: Association between promoter-1607 polymorphism of MMP1 and lumbar disc disease in Southern Chinese. BMC Med Genet 9:38,2008

27. Takahashi M, Haro H, Wakabayashi Y, Kawa-uchi T, Komori $\mathrm{H}$, Shinomiya $\mathrm{K}$ : The association of degeneration of the intervertebral disc with $5 \mathrm{a} / 6 \mathrm{a}$ polymorphism in the promoter of the human matrix metalloproteinase-3 gene. J Bone Joint Surg $\mathrm{Br}$ 83(4):491-495, 2001

28. Tan H, Zhao J, Jiang J, Ren Y: Association of the polymorphism of DR4 with the risk and severity of lumbar disc degeneration in the Chinese Han population. Scand J Clin Lab Invest 72:576-579, 2012

29. Varlotta GP, Brown MD, Kelsey JL, Golden AL: Familial predisposition for herniation of a lumbar disc in patients who are less than twenty-one years old. J Bone Joint Surg Am 73(1):124-128, 1991

30. Vo NV, Hartman RA, Yurube T, Jacobs LJ, Sowa GA, Kang JD: Expression and regulation of metalloproteinases and their inhibitors in intervertebral disc aging and degeneration. Spine J 13(3):331-341, 2013

31. Yuan HY, Tang Y, Lei L, Xiao GB, Liang YX, Wang S, Xia ZL: Synergistic interaction between MMP-3, VDR gene polymorphisms and occupational risk factors on lumbar disc degeneration. Zhonghua Lao Dong Wei Sheng Zhi Ye Bing Za Zhi 28(5):334-338, 2010 (In Chinese)

32. Zawilla NH, Darweesh $\mathrm{H}$, Mansour N, Helal S, Taha FM, Awadallah M, El Shazly R: Matrix metalloproteinase-3, vitamin $D$ receptor gene polymorphisms, and occupational risk factors in lumbar disc degeneration. J Occup Rehabil 24(2):370-381, 2014

33. Zigouris A, Alexiou GA, Batistatou A, Voulgaris S, Kyritsis AP: The role of matrix metalloproteinase 9 in intervertebral disc degeneration. J Clin Neurosci 18(10):1424-1425, 2011

34. Zigouris A, Batistatou A, Alexiou GA, Pachatouridis D, Mihos E, Drosos D, Fotakopoulos G, Doukas M, Voulgaris S, Kyritsis AP: Correlation of matrix metalloproteinases-1 and-3 with patient age and grade of lumbar disc herniation: Clinical article. Spine 14(2):268-272, 2011 